\title{
Immunohistochemical and molecular study on the protective effect of curcumin against hepatic toxicity induced by paracetamol in Wistar rats
}

\author{
Mohamed Mohamed Soliman ${ }^{1,2^{*}}$, Mohamed Abdo Nassan ${ }^{3}$ and Tamer Ahmed Ismail ${ }^{1,4}$
}

\begin{abstract}
Background: An overdose of paracetamol is a frequent reason for liver and renal toxicity and possible death and curcumin has hepatoprotective properties against liver damage. The exact mechanism of such protection is not clear. Therefore, this study was conducted to examine the molecular levels of the protective effect of curcumin on paracetamol overdose induced hepatic toxicity in rats.

Methods: Male Wistar rats were allocated into 4 groups. Control group, administered corn oil; curcumin group, administered curcumin (400 mg/kg BW daily intra-gastric) dissolved in corn oil; paracetamol group, administered corn oil with a single dose of paracetamol $(500 \mathrm{mg} / \mathrm{kg} \mathrm{BW}$ intra-gastric) and protective group, administered curcumin with a single dose of paracetamol. Curcumin was administered for 7 successive days, while paracetamol was administered at day six of treatment. Blood and liver tissues were collected for biochemical, histopathological, immunohistochemical and molecular examination.

Results: Serum analysis revealed an alteration in parameters of kidney and liver. A decrease in the antioxidant activity of liver was recorded in paracetamol group while curcumin administration restored it. Histopathological findings showed an extensive coagulative necrosis in hepatocytes together with massive neutrophilic and lymphocytic infiltration. Immunostaining of liver matrix metalloproteinase-8 (MMP-8) in paracetamol administered rats showed an increase in MMP-8 expression in the area of coagulative necrosis surrounding the central vein of hepatic lobules. Curcumin administration decreased MMP-8 expression in liver of paracetamol administered rats. Gene expression measurements revealed that paracetamol decreased the expression of antioxidant genes and increased the expression of interleukin-1 $\beta$ (IL-1 $\beta$ ), IL-8, tumor necrosis factor- $\alpha$ (TNF- $\alpha$ ) and acute phase proteins. Curcumin administration ameliorated paracetamol-induced alterations in genes expression of antioxidant and inflammatory cytokines.
\end{abstract}

Conclusion: The results clarified the strong protective effect of curcumin on paracetamol induced hepatic toxicity in rats at the immunohistochemical and molecular levels.

Keywords: Curcumin, Hepatic toxicity, Paracetamol, Cytokines expression, MMP-8 immunostaining, Wistar rats

\footnotetext{
* Correspondence: mohamedsoliman8896@yahoo.com

${ }^{1}$ Medical Laboratory Department, Faculty of Applied Medical Sciences, Taif

University, Turabah, Saudi Arabia

${ }^{2}$ Department of Biochemistry, College of Veterinary Medicine, Faculty of

Veterinary Medicine, Benha University, P.O. 13736, Moshtohor, Egypt

Full list of author information is available at the end of the article
} 


\section{Background}

Curcumin (CUR); a member of the ginger family Zingiberaceae; (1,7-bis [4-hydroxy-3-methoxyphenyl] -1,6heptadiene-3,5-dione) is a hydrophobic polyphenol compound. It is found in the rhizome of the herb Curcuma longa, which is commonly known as turmeric [1]. Turmeric is a widely used in therapeutic preparations against anorexia, coryza (rhinitis), herpes zoster, acne, cough, urinary tract diseases, diabetic wounds, hepatic disorder, rheumatism and sinusitis [2]. It is used as a food spice, additive, flavoring, preservative and as coloring agent in foods and textiles [3]. Curcumin has several activities including antioxidant [4], antimicrobial [5], anti-inflammatory [6], antiviral [7], anti-carcinogenic [8] and anti-diabetic [9]. Curcumin has hepatoprotective properties $[10,11]$ against liver damage in animals induced by carbon tetrachloride [12] and aflatoxin B [13]. Moreover, curcumin has silymarin-like actions [14] and antiapoptotic activity both in vitro and in vivo to prevent hepatic injury [15].

Paracetamol (PRM); acetaminophen or N-acetyl-paminophenol (APAP); is a widely analgesic medication in many countries. An overdose of paracetamol is a frequent reason for liver and renal toxicity and possible death [16]. The exact mechanism of such toxicity is not clear. However, the most studies have focused on PRM effects on antioxidant levels in blood and tissue [15], liver and kidney function [11]. High doses of PRM cause glutathione depletion, apoptosis and cell death [17]. PRM is metabolized in the liver by cytochrome P450 to $N$-acetyl- $p$-benzoquinone imine (NAPQI). NAPQI reacts with glutathione $(\mathrm{GSH})$, therfore overdoses of paracetamol may result in a depletion of hepatocellular GSH [18]. GSH exhaustion will cause NAPQI to binds with cellular proteins leading to mitochondrial dysfunction, oxidative stress, lipid peroxidation, DNA fragmentation, massive hepatocyte necrosis, liver damage and death [19]. The chemicals such as $\mathrm{N}$-acetyl cysteine were used to prevent paracetamol toxicity [20]. Narrow therapeutic window and toxicity together with the adverse effects of $\mathrm{N}$-acetyl cysteine encourage us to search for an alternative safe therapeutic medication to overcome paracetamol overdose and hepatic toxicity.

Matrix metalloproteinases is a family of $23 \mathrm{Zn2}{ }^{+-}$and $\mathrm{Ca}^{+-}$dependent endoproteases [21]. These enzymes are very effective in breaking down the major protein components of the extracellular matrix and basement membrane. Matrix metalloproteinase-8 (MMP-8) is a member of metalloproteinases and is a central mediator in acute lethal hepatitis. MMP- 8 deficient mice are markedly protected against TNF- $\alpha$ induced lethal hepatitis [22]. Downexpression of MMP-8 is associated with a decrease in mortality of rats with sepsis [23]. MMP-8 regulates expression of tumor necrosis factor- $\alpha$ (TNF- $\alpha)$, interleukin- $1 \beta$ (IL-1 $\beta$ ), and other inflammatory cytokines [24].
The liver is a pivotal organ that removes and inactivates toxic substances and drugs to be excreted in urine. Hepatic toxicity is attributed primarily to the changes in oxidative stress and alteration in acute phase proteins [25]. Liver is the first organ to be considered when the effects of environmental pollutants and toxins are investigated. Most of the substances absorbed by the intestine pass first to liver, where toxins and heavy metals are accumulated and inactivated [26]. Therefore, the condition of liver is important for our safety and health and its damage or disease is associated with DNA, protein, and lipid damage [27]. Most of published data focused mainly on serum biochemical alterations induced by curcumin on paracetamol overdose without a precise description about the changes in gene expression occurred during hepatic toxicity. So, the present study was aimed to examine the protective effect of curcumin against hepatic toxicity induced by paracetamol in Wistar rats based on immunohistochemical and molecular studies.

\section{Methods \\ Chemicals and kits}

Acetaminophen, ethidium bromide and agarose were purchased from Sigma-Aldrich (St. Louis, MO, USA). The Wistar albino rats were purchased from King Fahd center for Scientific Research, King Abdel-Aziz University, Jeddah, Saudi Arabia. Serologic kits for glutamate pyruvate transaminase (GPT), Glutamate oxalacetate transaminase (GOT), catalase, malondialdehyde (MDA), albumin and urea were purchased from Bio-diagnostic Co., Dokki, Giza, Egypt. The deoxyribonucleic acid (DNA) ladder was purchased from MBI, Fermentas, Thermo Fisher Scientific, USA. Qiazol for RNA extraction and oligo dT primer were purchased from QIAGEN (Valencia, CA, USA). AntiMMP-8 primary antibody and rat $\mathrm{ABC}$ staining system were purchased from Santa Cruz Biotechnology (Santa Cruz, CA, USA).

\section{Animals, experimental design and sampling}

All animal procedures were approved by the Ethical Committee Office of the dean of scientific affairs of Taif University, Saudi Arabia. Forty eight male Sprague Dawley rats, 3 months old, weighing 200-280 g were used for this study. For acclimatization, animals were kept under observation for 7 days before the onset of the experiment. The animals were kept at 12-h lightdark cycle and gained access to food and water ad libitum. Three independent experiments were carried out for each treatment. Rats were randomly divided into 4 groups as follows:

Control group (CTR) served as negative control and received corn oil orally. Curcumin group (CUR) received curcumin dissolved in corn oil orally in a dose of 400 $\mathrm{mg} / \mathrm{kg}$ BW daily for 7 days. Paracetamol group (PRM) 
received single intra-gastric dose of paracetamol $(500 \mathrm{mg}$ $/ \mathrm{kg} \mathrm{BW}$ intra-gastric) in water, 24 hours before sampling and was receiving corn oil orally for 7 days. Protective group (CUR + PRM) received curcumin dissolved in corn oil (400 mg/kg BW) daily for 7 days and on day six paracetamol $(500 \mathrm{mg} / \mathrm{kg}$ BW intra-gastric) was administered. The doses of paracetamol and curcumin were determined based on the studies of Zhang et al. [28] and Tarasub et al. [29], respectively. Twenty four hours after administration of tested chemicals, all animals (4 rats per treatment and three independent experiments for each treatment) were sacrificed after anesthetization by diethyl ether inhalation. Blood and tissues were collected from slaughtered rats. Serum was extracted after blood centrifugation for $10 \mathrm{~min}$ at $4000 \times \mathrm{g}$. For gene expression, liver tissues were kept in $\mathrm{TRIzol}^{\circ} \mathrm{re}-$ agent (Life Technologies, USA) at $-80^{\circ} \mathrm{C}$ in deep freezer for ribonucleic acid (RNA) extraction and in 10\% neutral buffered formalin (NBF) at room temperature for 24 hours for histopathological and immunohistochemical study.

\section{Determination of liver antioxidant activity}

For catalase and MDA activity measurements, one gram of liver tissues was homogenized in $5 \mathrm{ml}$ of cold buffer (50 mM potassium phosphate buffer; PBS, $\mathrm{pH}$ 7.4) for catalase and MDA. Cold buffer of catalase activity contains 1 $\mathrm{mM}$ EDTA and $1 \mathrm{~mL} / \mathrm{l}$ Triton X-100. After centrifugation at $4000 \times g$ for 15 minutes at $4^{\circ} \mathrm{C}$, the supernatant was removed and stored frozen at $-80^{\circ} \mathrm{C}$ until the time of analysis of catalase (U/g tissue) and MDA (nmol/g tissue). The activities of catalase and MDA were determined by ELISA reader (Absorbance Microplate Reader ELx 800TM BioTek $^{\circ}$, Seattle, WA, USA). Results were calculated according to the manufacturer's instructions.

\section{Liver histopathology}

After anesthetization of rats with diethyl ether and sacrifice, the liver was removed and fixed overnight in a $10 \%$ NBF solution. Fixed tissues were processed routinely and after washing and preservation in $70 \%$ ethanol, dehydration in ascending grades of ethanol, clearing in xylene, paraffin wax embedding, casting and cutting $5 \mu \mathrm{m}$ sections, they were placed on top of glass slides. The slides were stained with Mayer's hematoxylin and eosin ( $\mathrm{H}$ and $\mathrm{E})$ [30]. Tissue slides were visualized using a Wolfe S9-0982 microscope and figures were captured using Canon Power-Shot SX500 IS digital camera.

\section{Liver immunohistochemical staining of MMP-8}

For immunohistochemistry, tissue sections were deparaffinized then treated with $3 \% \mathrm{H}_{2} \mathrm{O}_{2}$ for 10 min to inactivate endogenous peroxidases, heated in $10 \mathrm{mM}$ citrate buffer at $121^{\circ} \mathrm{C}$ for $30 \mathrm{~min}$ for antigen retrieval, blocked in 5\% normal serum for $20 \mathrm{~min}$, and incubated with a primary polyclonal rabbit anti-rat antibody specific for
MMP-8 (1:100 in PBS, Cat \# sc-30069; Santa Cruz Biotechnology) overnight at $4{ }^{\circ} \mathrm{C}$. After three extensive washes with PBS, sections were incubated with a biotin-conjugated secondary antibody (1:2,000 in PBS; Cat \# sc-2040) for $20 \mathrm{~min}$ at $32^{\circ} \mathrm{C}$. After further incubation with horseradish peroxidase (HRP)-labeled streptavidin, antibody binding was visualized with diaminobenzidine (DAB) and sections were counterstained with hematoxylin for 10 seconds at room temperature based on manufacture instruction. For negative control, primary antibody was replaced with PBS alone. Tissue slides were examined using a Wolfe S9-0982 microscope and images were captured using Canon Power-Shot SX500 IS digital camera. For the expression of MMP-8, five fields per section and 4 sections from 4 different rats per treatment were examined.

\section{Gene expression analysis RNA extraction}

Total RNA was extracted from liver tissue samples (approximately $100 \mathrm{mg}$ per sample) of experimental rats. Liver samples were flash frozen in liquid nitrogen and subsequently stored at $-70^{\circ} \mathrm{C}$ in $1 \mathrm{ml}$ Qiazol (QIAGEN, Valencia, CA, USA). Frozen samples were homogenized using a Polytron 300 D homogenizer (Brinkman Instruments, Westbury, NY, USA). Then, $0.3 \mathrm{ml}$ chloroform was added to the homogenate. The mixtures were shaken for $30 \mathrm{sec}-$ onds followed by centrifugation at $4^{\circ} \mathrm{C}$ and $16,400 \times g$ for $15 \mathrm{~min}$. The supernatant was transferred to a new set of tubes, and an equal volume of isopropanol was added to the samples, shaken for 15 seconds and centrifuged at $4^{\circ} \mathrm{C}$ and $16,400 \times g$ for $15 \mathrm{~min}$. The RNA pellets were washed with $70 \%$ ethanol, briefly dries up, and then dissolved in diethylpyrocarbonate (DEPC) water. RNA concentration and purity were determined spectrophotometrically at 260 $\mathrm{nm}$. The RNA integrity was confirmed in $1.5 \%$ denaturated agarose gel stained with ethidium bromide. The ratio of the 260/280 optical density of all RNA samples was 1.7-1.9.

\section{Complementary deoxyribonucleic acid (cDNA) synthesis}

For cDNA synthesis, a mixture of $3 \mu \mathrm{g}$ total RNA and 0.5 ng oligo dT primer (Qiagen Valencia, CA, USA) in a total volume of $11 \mu \mathrm{l}$ sterilized DEPC water was incubated in the Bio-Rad T100 ${ }^{\text {Ts }}$ Thermal cycle at $65^{\circ} \mathrm{C}$ for $10 \mathrm{~min}$ for denaturation. Then, $2 \mu \mathrm{l}$ of 10X RT-buffer, $2 \mu \mathrm{l}$ of $10 \mathrm{mM}$ dNTPs and $100 \mathrm{U}$ Moloney Murine Leukemia Virus (MMuLV) Reverse Transcriptase (SibEnzyme. Ak, Novosibirsk, Russia) were added and the total volume was completed up to $20 \mu \mathrm{l}$ by DEPC water. The mixture was then reincubated in $\mathrm{BIO}-\mathrm{RAD}$ thermal cycler at $37^{\circ} \mathrm{C}$ for one hour, then at $90^{\circ} \mathrm{C}$ for $10 \mathrm{~min}$ to inactivate the enzyme.

\section{Semi-quantitative PCR analysis}

For semi-quantitative RT-PCR analysis, specific primers for examined genes (Table 1) were designed using Oligo-4 
Table 1 PCR conditions for rat antioxidants, cytokines and acute phase proteins genes

\begin{tabular}{|c|c|c|c|}
\hline Gene & Forward primer $\left(5^{\prime}-3^{\prime}\right)$ & Reverse primer $\left(5^{\prime}-3^{\prime}\right)$ & PCR cycles and conditions \\
\hline GST (575 bp) & GCTGGAGTGGAGTTTGAAGAA & GTCCTGACCACGTCAACATAG & 35 cycles, $55^{\circ} \mathrm{C} 1 \mathrm{~min}$ \\
\hline GPx (406 bp) & AAGGTGCTGCTCATTGAGAATG & CGTCTGGACCTACCAGGAACTT & 40 cycles $57^{\circ} \mathrm{C} 1 \mathrm{~min}$ \\
\hline SOD (410 bp) & AGGATTAACTGAAGGCGAGCAT & TCTACAGTTAGCAGGCCAGCAG & 35 cycles, $55^{\circ} \mathrm{C} 1 \mathrm{~min}$ \\
\hline Catalase (652 bp) & GCGAATGGAGAGGCAGTGTAC & GAGTGACGTTGTCTTCATTAGCACTG & 35 cycles, $55.5^{\circ} \mathrm{C} 1 \mathrm{~min}$ \\
\hline IL-1 $\beta$ (218 bp) & ATGGCAACCGTACCTGAACCCA & GCTCGAAAATGTCCCAGGAA & 30 cycles, $61^{\circ} \mathrm{C} 1 \mathrm{~min}$ \\
\hline TNF-a (256 bp) & CCACCACGCTCTTCTGTCTAC & ACCACCAGTTGGTTGTCTITG & 30 cycles, $58^{\circ} \mathrm{C} 1 \mathrm{~min}$ \\
\hline IL-8 (460 bp) & CTCCAGCCACACTCCAACAGA & CACCCTAACACAAAACAGAT & 35 cycles, $56^{\circ} \mathrm{C} 1 \mathrm{~min}$ \\
\hline IL-10 (320bp) & GGAGTGAAGACCAAAGG & TCTCCCAGGGAATTCAAATG & $30 \mathrm{cycles}, 57^{\circ} \mathrm{C} 1 \mathrm{~min}$ \\
\hline a2 -macroglobulin (325 bp) & GCTCCTGTCTGTITCCTTAGTT & ATTGGCCTTTCGTGGTTTAG & $30 \mathrm{cycles}, 56^{\circ} \mathrm{C} 1 \mathrm{~min}$ \\
\hline a1-glycoprotein (230 bp) & GCTITCCTCCTGACAACGCTG & GGCTIITGTTGTTTGCTTCTATTTC & 30 cycles, $55^{\circ} \mathrm{C} 1 \mathrm{~min}$ \\
\hline GAPDH (309bp) & AGATCCACAACGGATACATT & TCCCTCAAGATTGTCAGCAA & 25 cycles, $52^{\circ} \mathrm{C} 1 \mathrm{~min}$ \\
\hline
\end{tabular}

computer program and synthesized by Macrogen (Macrogen Company, GAsa-dong, Geumcheon-gu. Korea). PCR was conducted in a final volume of $25 \mu$ l consisting of $1 \mu \mathrm{l}$ cDNA, $1 \mu \mathrm{l}$ of $10 \mathrm{pM}$ of each primer (forward and reverse), and $12.5 \mu \mathrm{l}$ PCR master mix (Promega Corporation, Madison, WI, USA), the volume was brought up to $25 \mu \mathrm{l}$ using sterilized, deionized water. PCR was carried out using Bio-Rad $\mathrm{T}_{100}{ }^{\mathrm{rx}}$ Thermal Cycle machine with the cycle sequence at $94^{\circ} \mathrm{C}$ for 5 minutes one cycle, followed by variable cycles (Table 1 ) each of which consists of denaturation at $94^{\circ} \mathrm{C}$ for one minute, annealing at the specific temperature corresponding to each primer (Table 1) and extension at $72^{\circ} \mathrm{C}$ for one minute with an additional final extension at $72^{\circ} \mathrm{C}$ for 7 minutes. As a reference, expression of glyceraldehyde-3-phosphate dehydrogenase $(\mathrm{G} 3 \mathrm{PDH})$ mRNA was examined (Table 1$)$. PCR products underwent electrophoresis on 1.5\% agarose (Bio Basic, Markham, ON, Canada) gel stained with ethidium bromide in TBE (Tris-Borate-EDTA) buffer. PCR products were visualized under UV light and photographed using gel documentation system. The intensities of the bands from four different rats per group and three independent experiments were quantified densitometrically using Image J software version 1.47 (http://imagej.en.softonic.com/).

\section{Statistical analysis}

Results are shown as means \pm standard error of means (SEM). Data were analyzed using analysis of variance
(ANOVA) and post hoc descriptive tests by SPSS software version 11.5 for Windows (SPSS, IBM, Chicago, IL, USA) with $\mathrm{p}<0.05$ regarded as statistically significant. Regression analysis was performed using the same software.

\section{Results}

\section{Renal and hepatic biochemical measurements}

Because of the cross association between urea synthesis in liver and its secretion in kidney, the changes in the parameters of kidney and liver after induction of paracetamol toxicity were examined. Paracetamol overdose increased serum levels of GPT, GOT, urea and albumin (Table 2). While, administration of curcumin together with paracetamol inhibited such increase in kidney and liver parameters compared to paracetamol group (Table 2). Curcumin administration alone has no significant effect on examined kidney and liver parameters.

\section{Hepatic antioxidant activity}

The results about the protective effect of curcumin on MDA as oxidative stress marker, and catalase as antioxidant enzyme are illustrated in Table 3. The current results revealed that MDA increased significantly $(P<$ $0.05)$ in paracetamol administered rats compared to control group $(18.2 \pm 0.5$ for paracetamol group vs. $9.78 \pm$ 1.9 for control). Co-administration of curcumin with paracetamol normalized the increase in MDA activity

Table 2 Protective effect of curcumin on paracetamol induced changes in serum levels of renal and hepatic parameters in Wistar rats

\begin{tabular}{ccccc}
\hline & Control & Curcumin & Paracetamol & Curcumin + Paracetamol \\
\hline Urea (mg/dl) & $35.6 \pm 3.8$ & $35.3 \pm 2.3$ & $42.0 \pm 1.5^{*}$ & $31.0 \pm 1.0^{\#}$ \\
Albumin (g/d) & $3.2 \pm 0.1$ & $3.1 \pm 0.1$ & $4.8 \pm 0.4^{*}$ & $3.5 \pm 0.1^{\#}$ \\
GOT (U/L) & $83 \pm 2$ & $72.7 \pm 9.6$ & $156 \pm 9.4^{*}$ & $90.3 \pm 3.7^{\#}$ \\
GPT(U/L) & $58.3 \pm 6$ & $64.7 \pm 6.01$ & $136 \pm 27.9^{*}$ & $98 \pm 4.9^{\#}$ \\
\hline
\end{tabular}

Values are means \pm standard error (SEM) for 3 independent experiments per each treatment. Values are statistically significant at ${ }^{*} \mathrm{p}<0.05$ Vs. control and \#p $<0.05$ Vs. paracetamol group. 
Table 3 Protective effect of curcumin on paracetamol induced changes in hepatic antioxidant activity in Wistar rats

\begin{tabular}{lcccc}
\hline & Control & Curcumin & Paracetamol & Curcumin + Paracetamol \\
\hline MDA (nmol/g tissue) & $9.78 \pm 1.9$ & $10.7 \pm 1.0$ & $18.2 \pm 0.5^{*}$ & $12.6 \pm 0.4^{\#}$ \\
Catalase (U/g tissue) & $33 \pm 6.1$ & $37 \pm 1.1^{*}$ & $21 \pm 0.4^{*}$ & $33.9 \pm 2.6^{\#}$ \\
\hline
\end{tabular}

Values are means \pm standard error (SEM) 3 independent experiments per each treatment. Values are statistically significant at ${ }^{*} p<0.05$ Vs. control and \#p $<0.05$ Vs. paracetamol group.

observed in paracetamol group $(12.6 \pm 0.4$ for paracetamol plus curcumin group vs. $18.2 \pm 0.5$ for paracetamol group). In paracetamol group, catalase activity was decreased significantly compared to control group ( $21 \pm 0.4$ for paracetamol vs. $33 \pm 6.1$ for control). For curcumin administered group, there is a significant increase in catalase activity (U/g tissue) ( $37 \pm 1.1$ for curcumin $v s$. $9.78 \pm 1.9$ for control). Administration of curcumin plus paracetamol inhibited significantly the decrease in catalase activity observed in paracetamol group $(33.9 \pm 2.6$ for curcumin plus paracetamol vs. $21 \pm 0.4$ for paracetamol).

\section{Liver histopathology}

The liver of the control group showed normal hepatic architecture with presence of a central vein surrounded by normal radiating hepatic cords with normal hepatic sinusoids in between (Figure 1A). Liver of curcumin administered rats showed normal hepatic lobules, consisting of a central vein surrounded by radiating hepatocyte plates with normal portal tracts surround the classical lobules (Figure 1B). In contrast, liver of paracetamol intoxicated group showed an extensive coagulative necrosis of hepatocytes together with massive neutrophilic and lymphocytic infiltration (Figure 1C). Interestingly, administration of curcumin together with paracetamol in the protective group showed an improvement of hepatic toxicity with presence of small degenerated area together with normalization in liver architectures (Figure 1D).

\section{Immunohistochemical staining of MMP-8 in liver}

Immuno-stained liver of control and curcumin groups for MMP-8 expression showed normal hepatic architecture

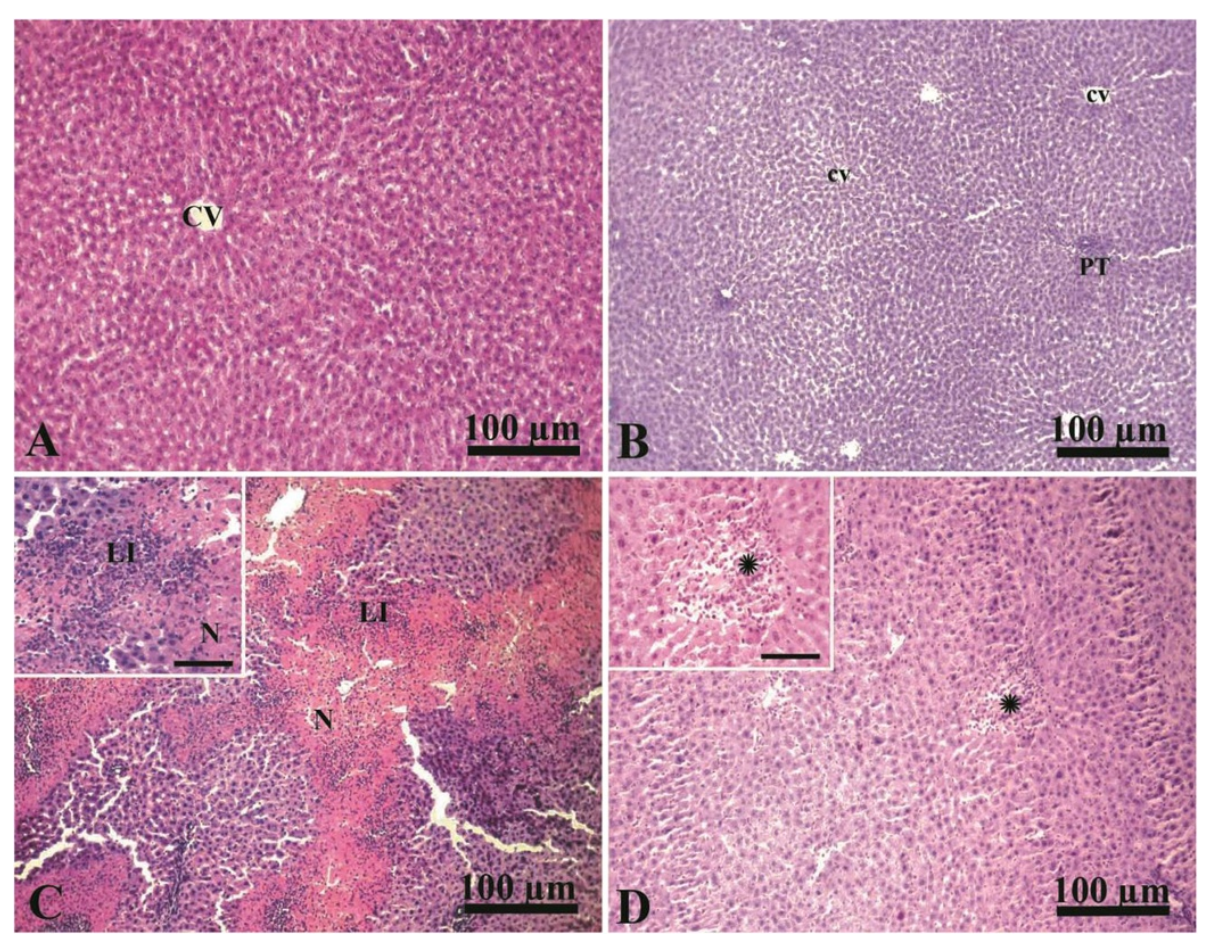

Figure 1 Photographs of liver histopathology from CTR, CUR, PRM, and CUR + PRM administered rats stained with H \& E. A, liver of CTR group showing normal hepatic architecture with presence of a central vein (CV) surrounded by normal radiating hepatic cords (arrow). B, liver of CUR group showing normal hepatic lobules, consisting of a central vein (cv) surrounded by radiating hepatocyte plates with normal portal tracts (PT) surround the classical lobules. C, liver of PRM intoxicated group showing extensive coagulative necrosis of hepatocytes (N) together with dense leukocytic infiltration (neutrophils and lymphocytes; LI). D, liver of CUR + PRM administered group showing improvement of hepatic toxicity with presence of small degenerated areas $\left(^{*}\right)$. Scale bar for all photographs is $100 \mu \mathrm{m}$. Inserts are high magnification fields in $\mathbf{C}$ and $\mathbf{D}$ with scale bars of $50 \mu \mathrm{m}$. 
(Figure 2A-B). Liver of paracetamol intoxicated group showed an increase in the expression of MMP-8 in the cytoplasm in the area of coagulative necrosis surrounding hepatic central vein (Figure $2 \mathrm{C}$ ) compared with that of negative control (Figure 2D). The liver of the protective group administered curcumin plus paracetamol showed no expression for MMP-8 (Figure 2E) supporting the protective effect of paracetamol on hepatic toxicity.

\section{Semi-quantitative RT-PCR analysis of hepatic antioxidant enzymes}

RT-PCR analysis for antioxidants expression is illustrated in Figure 3 (A-D). Parallel to tissue catalase activity (Table 3), mRNA expression of glutathione-S-transferase (GST), glutathione peroxidase (GPx), superoxide dismutase (SOD) and catalase was decreased significantly in paracetamol administered group and was increased in curcumin administered group (Figure 3 A-D). Curcumin administration plus paracetamol reversed the decrease in antioxidants expression observed in paracetamol administered groups.

\section{Semi-quantitative RT-PCR analysis of hepatic cytokines expression}

Paracetamol up-regulated significantly $(\mathrm{p}<0.05)$ interleukin$1 \beta$ (IL-1 $\beta)$ and tumor necrosis factor-alpha (TNF- $\alpha$ ) expression compared to control and curcumin administered groups (Figure 4 A-C). Curcumin alone has a minor effect on IL-1 $\beta$, TNF- $\alpha$ and IL-8 expressions; however, it
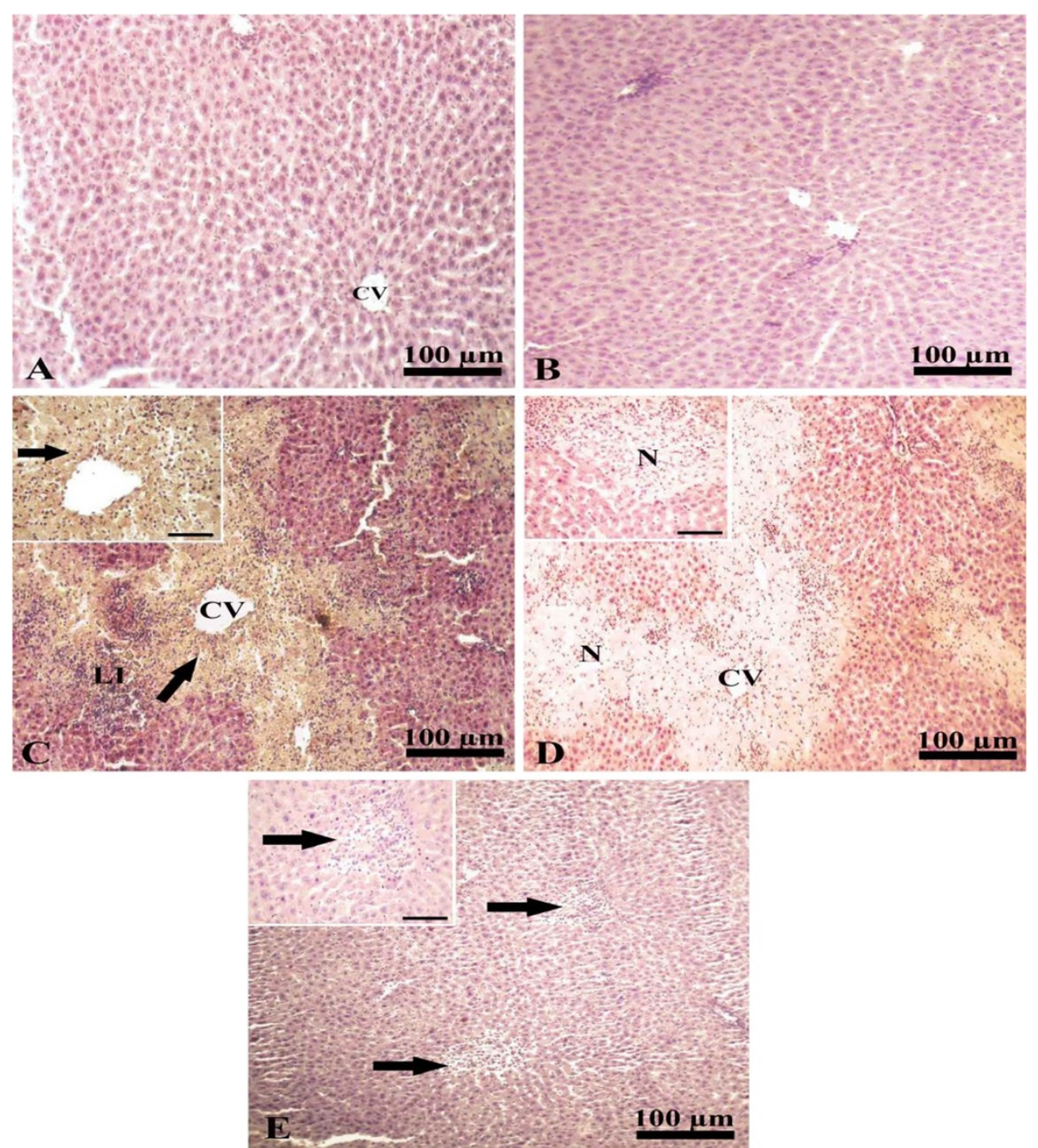

Figure 2 Immunohistochemical staining of MMP-8 in liver. A and $\mathbf{B}$, liver of CTR and CUR administered groups immunostained showing normal hepatic architecture with presence of a central vein (cv) and normal hepatic cords. C, liver of paracetamol intoxicated group showing increased expression of mmp-8 (arrow) in the necrotic area surrounding central vein (cv) together with leukocytic infiltration (neutrophils and lymphocytes; LI). D, liver of control negative paracetamol intoxicated group with no expression of mmp-8 in the necrotic area ( $\mathrm{N}$ ) around central vein (CV). E, liver of paracetamol intoxicated group treated with curcumin immunostained showing no expression of mmp-8 (arrows). Scale bar for photos from $\mathbf{A}$ to $\mathbf{E}$ is $100 \mu \mathrm{m}$. Inserts are high magnification fields in $\mathbf{C}, \mathbf{D}$ and $\mathbf{E}$ with scale bars of $50 \mu \mathrm{m}$. 


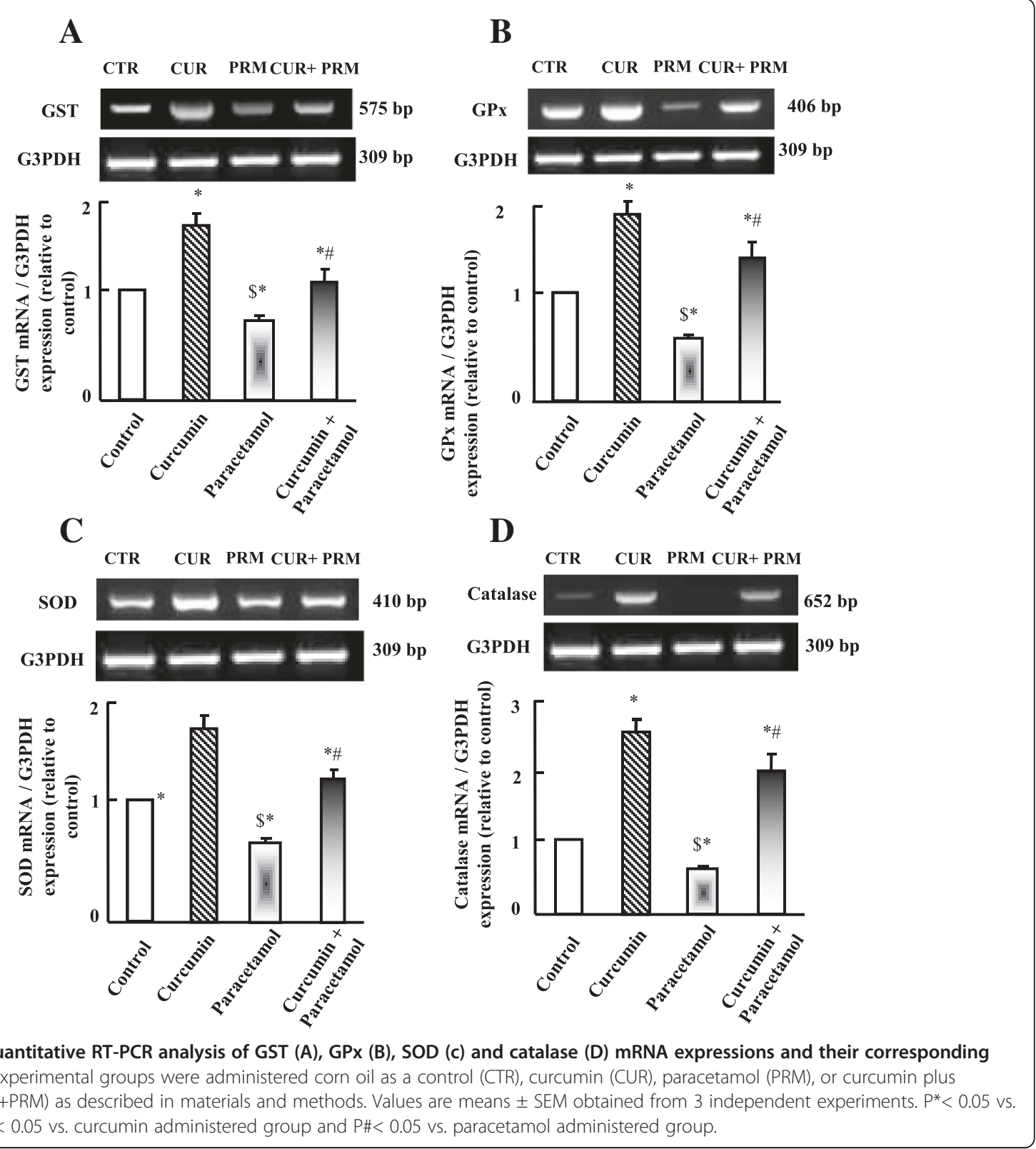

increased IL-10 expression. Curcumin plus paracetamol administration normalized the increase in IL-1 $\beta$, IL- 8 and TNF- $\alpha$ expressions that are observed in paracetamol administered group. Moreover, curcumin administration plus paracetamol increased the expression of regenerative IL-10 (Figure 4D).

Semi-quantitative RT-PCR analysis of hepatic acute phase proteins expression

To explore the possible involvement of acute phase proteins in curcumin protective effect, the expressions of $\alpha 1$ acid glycoprotein (AGP) and $\alpha-2$ macroglobulin $(\alpha-2 \mathrm{M})$ were examined. AGP expression increased in paracetamol group compared to control and curcumin administered groups (Figure 5A). Curcumin administration plus paracetamol normalized AGP expressions compared to paracetamol, curcumin and control administered groups as shown in Figure 5 (A). Unlike AGP is $\alpha-2 M$ mRNA expression, $\alpha-2 \mathrm{M}$ was down-regulated in paracetamol group compared to control and curcumin administered groups. Curcumin co-administration with paracetamol inhibited the down regulation in $\alpha-2 \mathrm{M}$ expression compared to paracetamol and control groups (Figure 5B).

\section{Discussion}

This study demonstrated that, curcumin administration attenuated hepatic toxicity induced by paracetamol overdose through the re-impairment of antioxidant capacity 


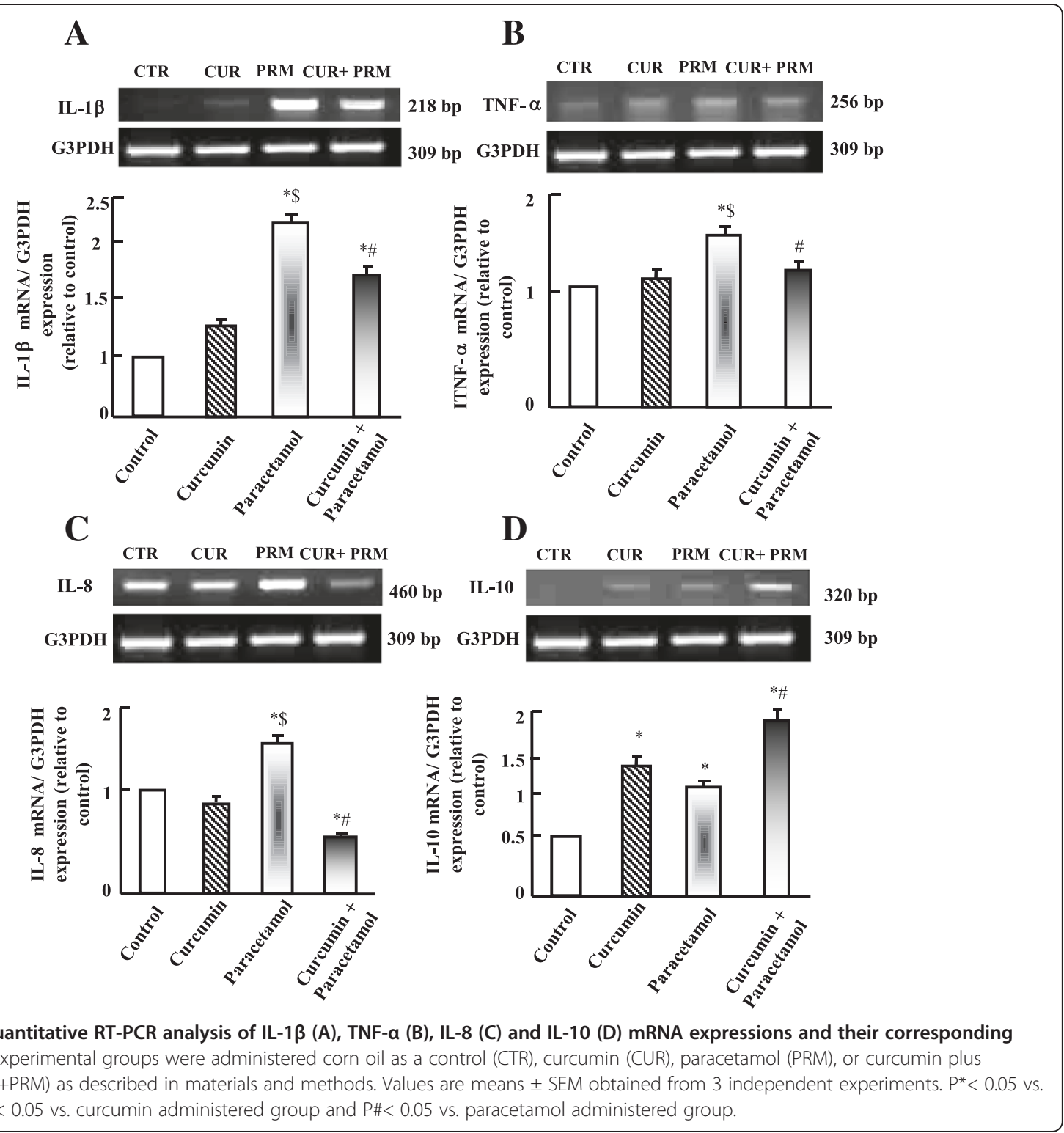

of hepatic cells. Curcumin decreased the MMP-8 expression and some cytokines that initiate the inflammatory cascade of the body. In Kheradpezhouh et al. [31] and Yousef et al. [32] studies, they focused on the alterations in serum levels of liver and kidney parameters, but our study focused on the immunohistochemical and molecular attenuation of hepatic toxicity by curcumin.

Alterations in serum levels of hepatic transaminases (GPT and GOT) were used as markers for liver damage and disease. In our study, there was a significant increase in GPT and GOT levels in paracetamol administered rats. Curcumin administration ameliorated both liver and kidney changes confirming the protective role of curcumin against hepatic toxicity induced by paracetamol overdose and that is coincided with results of
Li et al. [15]. Moreover, it was reported that curcumin supplementation improved liver histopathology and showed an improvement in hepatic toxicity. MMP-8 plays an important role in progression and regulation of a variety of diseases, inflammatory response, blood pressure and cancer progression [21]. Our results showed an increase in MMP-8 expression during hepatic toxicity and it's down expression by curcumin in paracetamol group. Curcumin helped in the regeneration process of hepatic cells probably through cytokines expression as reported by our results and that reported by another study [21].

Lipid peroxidation and antioxidant potency (GST, SOD and catalase) of cells were used to assess the degree of hepatic cell stability and integrity [33]. Oxidative damage caused by paracetamol overdose was significantly attenuated 


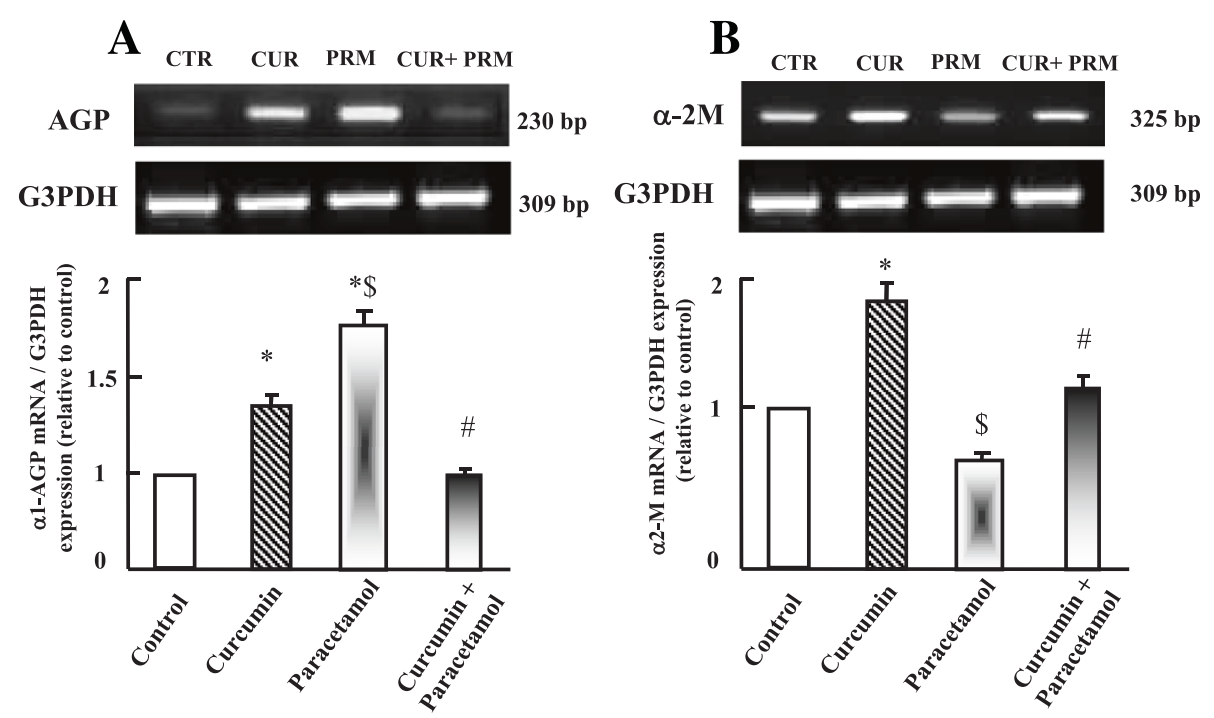

Figure 5 Semi-quantitative RT-PCR analysis of acute phase proteins AGP (A), and a-2M (B) mRNA expressions and their corresponding G3PDH in liver. Experimental groups were administered corn oil as a control (CTR), curcumin (CUR), paracetamol (PRM), or curcumin plus paracetamol (CUR+PRM) as described in materials and methods. Values are means \pm SEM obtained from 3 independent experiments. $P^{*}<0.05$ vs. control group, $\mathrm{P} \$<0.05$ vs. curcumin administered group and $\mathrm{P \#}<0.05$ vs. paracetamol administered group.

by curcumin administration. Therefore, we can postulate that curcumin could protect against free radical mediated oxidative stress by scavenging for free radicals that limit lipid peroxidation and attenuates antioxidants depletion [34]. Curcumin increased mRNA expressions of GST, GPx, SOD, and catalase. Additionally, curcumin attenuates antioxidants depletion and protects liver from paracetamol overdose-induced toxicity. Most of the antioxidants have either a phenolic functional group or a $\beta$-diketone group. Curcumin has a variety of functional groups. These functional groups include the $\beta$-diketone group, carboncarbon double bonds, and phenyl rings containing varying amounts of hydroxyl and methoxy substituents [35,36]. It has been suggested that curcumin was unable to prevent MDA production [37]. Curcumin is bio-transformed to dihydrocurcumin, tetrahydrocurcumin, and hexahydrocurcumin after intestinal absorption. These bio-transformed products are converted to glucuronide conjugates, which are more polar and have better absorption than curcumin. Therefore, the pharmacological actions of curcumin are mostly due to curcumin's hydrosoluble derivatives [38].

The phenolic and methoxy groups on the benzene rings of curcumin are important structural features that contribute to curcumin's antioxidant properties [39] and ability to reduce the amount of free radicals [40]. To confirm the antioxidant and anti-inflammatory activity of curcumin during hepatic toxicity, we examined the expression of antioxidants and acute phase cytokines. The antioxidant gene expression and secretion increased in curcumin administered rats compared to control group. Curcumin administration down-regulated the increase of IL- $1 \beta$, TNF- $\alpha$ and IL-8 expressions in paracetamol administered group [4]. IL- $1 \beta$, TNF- $\alpha$, and IL- 6 are the major inducers of acute phase response [41]. They act as hepatotrophic factors as evidenced by circulating levels of TNF- $\alpha$ and IL$1 \beta$ that are increased in rats with liver damage [42]. Curcumin modulates the inflammatory response by down-regulating the activity of cyclooxygenase-2, inducible nitrous oxide synthase, TNF- $\alpha$, IL-1 $\beta$, IL- 6 and IL- 8 secretion [43]. The results confirmed that curcumin decreased mRNA expression of IL-1 $\beta$, TNF- $\alpha$ and IL- 8 that are increased in liver of paracetamol administered group. In the current results curcumin regulated IL-8 expression in a way to initiate chemoattractant mechanism and consequently ameliorate inflammation. The inhibitory effect of curcumin on inflammatory cytokines expression is attributed to the reduction of the Ік/NF-кB signaling pathway [10]. Moreover, curcumin co-administration with paracetamol increased expression of IL-10, which is a known regenerative cytokine [44]. IL-10 is produced mainly by monocytes with pleiotropic actions [45]. IL-10 down regulates $\mathrm{T}$ helper 1 cytokines expression, inhibits IL-1 and IL-6 production [44], configures the development of the immune response and decrease pro-inflammatory cytokine expression [46]. Therefore, the increase in IL-10 expression is a mean to control the degree of toxicity induced by paracetamol and to counteract the increase in expression of IL- $1 \beta$ and TNF- $\alpha$.

The changes in plasma protein levels of acute phase reaction proteins cause modifications in the way of drug action, distribution in tissues, degradation and elimination [47]. One of the most interesting proteins of acute 
phase reaction is AGP. AGP is the principal basic protein that binds to drugs with significant clinical implications to control the inflammation cascade in the body $[47,48]$. For example, AGP is involved in some pharmacokinetics of some drugs such as drug-drug interactions to induce clinical consequences to reduce the degree of toxicity and inflammation [47]. Therefore the increase in AGP after paracetamol administration is reflex to indicate the degree of toxicity. Curcumin administration attenuated the upregulation of AGP expression to control the inflammation degree occurred in liver.

Alpha 2-macroglobulin is a large plasma protein produced mainly from liver and locally by macrophage, fibroblast and adrenocortical cells [49]. As known, $\alpha-2 \mathrm{M}$ inhibits fibrinolysis (inhibits plasmin synthesis) and acts as a protein carrier for numerous growth factors and cytokines among which is IL- $1 \beta$ [50]. $\alpha-2 \mathrm{M}$ secretion is decreased during acute liver inflammation [50]. In current study, $\alpha-2 \mathrm{M}$ expression is upregulated after curcumin administration and downregulated after paracetamol administration. Previous curcumin administration protected liver cells from paracetamol toxicity to counteract the biohazards induced by paracetamol through normalization of $\alpha-2 \mathrm{M}$ expression.

\section{Conclusions}

In summary, the current study showed that curcumin attenuates hepatic toxicity induced by paracetamol. The protective effect of curcumin occurred through the upregulation in antioxidants gene expression and downregulation in oxidative stress markers. Moreover, curcumin regulated MMP-8 and various cytokines expressions. Further in vitro studies are needed to outline the signaling pathways involved in curcumin actions during hepatic toxicity.

\section{Abbreviations \\ AGP: Alpha1-acid glycoprotein; APAP: N-acetyl-p-aminophenol; CDNA: Complementary deoxyribonucleic acid; CUR: Curcumin; DAB: Diaminobenzidine; DEPC: Diethylpyrocarbonate; DNA: Deoxyribonucleic acid; EDTA: Ethylenediamine tetra acetic acid; G3PDH: Glyceraldhyde-3-phosphate dehydrogenase; GSH: Glutathione; GPT: Glutamate pyruvate transaminase; GOT: Glutamate oxalacetate transaminase; GPx: Glutathione peroxidase; GST: Glutathione-S-transferase; $\mathrm{H}$ and E: Hematoxylin and eosin; HRP: Horseradish peroxidase; IL-1: Interleukin 1; MMP-8: Matrix metalloproteinase-8; MDA: Malondialdehyde; M-Mul V: Moloney Murine Leukemia Virus; NAPQI: $\mathrm{N}$-acetyl- $p$-benzoquinone imine; NBF: Neutral buffered formalin; PRM: Paracetamol; PBS: Phosphate buffer saline; RNA: Ribonucleic acid; RT-PCR: Reverse transcription polymerase chain reaction; SEM: Standard error of the mean; SOD: Superoxide dismutase; TNF-a: Tumor necrosis factor alpha; TBE: Tris-borate-EDTA; a-2M: a-2macroglobulin.}

\section{Competing interests}

The authors declare that they have no competing interests.

\section{Authors' contributions}

Conceived and designed the experiments: MMS, TAI. Performed Experiments: MMS MAN, TAl. Analyzed data: MMS, MAN. Biochemical Assays: MMS. Histopathology: MAN. Gene expression: MMS TAI. Data interpretations: MMS
MAN. Revision of manuscript: MMS TAl. All authors read and approved the final manuscript.

\section{Acknowledgements}

We greatly appreciate the contributions of authors to finish this study.

\section{Financial disclosure}

There is no financial support for this study and was supported on author's expenses.

\section{Author details}

'Medical Laboratory Department, Faculty of Applied Medical Sciences, Taif University, Turabah, Saudi Arabia. ${ }^{2}$ Department of Biochemistry, College of Veterinary Medicine, Faculty of Veterinary Medicine, Benha University, P.O. 13736, Moshtohor, Egypt. ${ }^{3}$ Department of Pathology, Faculty of Veterinary Medicine, Zagazig University, Zagazig, Egypt. ${ }^{4}$ Department of Physiology, Faculty of Veterinary Medicine, Zagazig University, Zagazig, Egypt.

Received: 22 August 2014 Accepted: 21 November 2014 Published: 29 November 2014

\section{References}

1. Altenburg JD, Bieberich AA, Terry C, Harvey KA, Vanhorn JF, Xu Z, Jo Davisson V, Siddiqui RA: A synergistic antiproliferation effect of curcumin and docosahexaenoic acid in SK-BR-3 breast cancer cells: unique signaling not explained by the effects of either compound alone. BMC Cancer 2011, 11:149.

2. Chattopadhyay I, Biswas K, Bandyopadhyay U, Banerjee RK: Turmeric and curcumin: biological actions and medicinal applications. Curr Sci 2004, 87:44-53.

3. Basnet $\mathrm{P}$, Skalko-Basnet $\mathrm{N}$ : Curcumin: an anti-inflammatory molecule from 1081 a curry spice on the path to cancer treatment. Molecules 2011, $16: 4567-4598$

4. Al-Jassabi S, Ahmed KA, Ameen M: Antioxidant effect of curcumin against microcystin-LR-induced renal oxidative damage in Balb/c mice. Trop J Pharm Res 2012, 11:5316.

5. Tajbakhsh S, Mohammadi K, Deilami I, Zandi K, Ramedani E, Asayesh G: Antibacterial activity of indium curcumin and indium diacetylcurcumin. Afr J Biotechnol 2008, 7:3832-3835.

6. Bereswill S, Munoz M, Fischer A, Plickert R, Haag L, Otto B, Kuhl AA, Loddenkemper C, Gobel UB, Heimesaat MM: Anti-inflammatory effects of resveratrol, curcumin and simvastatin in acute small intestinal inflammation. PLoS One 2010, 5(12):e15099.

7. Kutluay SB, Doroghazi J, Roemer ME, Triezenberg SJ: Curcumin inhibits herpes simplex virus immediate-early gene expression by a mechanism independent of p300/CBP histone acetyltransferase activity. Virology 2008, 373(1659):239-247.

8. Das L, Vinayak M: Anti-carcinogenic action of curcumin by activation of antioxidant defence system and inhibition of $\mathrm{NF}_{-\mathrm{K}} \mathrm{B}$ signalling in lymphoma bearing mice. Biosci Rep 2012, 32:161-170.

9. Aziz MT, El Ibrashy IN, Mikhailidis DP, Rezq AM, Wassef MA, Fouad HH, Ahmed HH, Sabry DA, Shawky HM, Hussein RE: Signaling mechanisms of a water soluble curcumin derivative in experimental type 1 diabetes with cardiomyopathy. Diabetol Metab Syndr 2013, 5:5-13.

10. Jobin C, Braham C, Russo MP, Juma B, Narula AS, Brenner DA, Sartor RB: Curcumin blocks cytokine-mediated NF-KB activation and proinflammatory gene expression by inhibiting inhibitory factor I-KB kinase activity. J Immunol 1999, 163:3474-3483.

11. Somanawat K, Thong-Ngam D, Klaikeaw N: Curcumin attenuated paracetamol overdose induced hepatitis. World J Gastroenterol 2013, 19:1962-1967.

12. Morsy MA, Abdalla AM, Mahmoud AM, Abdelwahab SA, Mahmoud ME: Protective effects of curcumin, a-lipoic acid, and $\mathrm{N}$-acetylcysteine against carbon tetrachloride-induced liver fibrosis in rats. J Physiol Biochem 2012, 68:29-35.

13. El-Agamy DS: Comparative effects of curcumin and resveratrol on aflatoxin B (1)-induced liver injury in rats. Arch Toxicol 2010, 84(5):389-396.

14. Girish C, Koner BC, Jayanthi S, Ramachandra Rao K, Rajesh B, Pradhan SC Hepatoprotective activity of picroliv, curcumin and ellagic acid compared to silymarin on paracetamol induced liver toxicity in mice. Fundam Clin Pharmacol 2009, 6:735-745 
15. Li G, Chen JB, Wang C, Xu Z, Nie H, Qin XY, Chen XM, Gong Q: Curcumin protects against acetaminophen-induced apoptosis in hepatic injury. World I Gastroenterol 2013, 19:7440-7446.

16. Zhao C, Sheryl D, Zhou YX: Effects of combined use of diallyl disulfide and Nacetyl-cysteine onacetaminophen hepatotoxicity in betanaphthoflavone pretreated mice. World J Gastroenterol 1998, 4:112-116.

17. Sun YM, Zhang HY, Chen DZ, Liu CB: Theoretical elucidation on the antioxidant mechanism of curcumin: a DFT study. Org Lett 2002 4:2909-2911.

18. Hinson JA, Reid AB, McCullough SS, James LP: Acetaminophen-induced hepatotoxicity: role of metabolic activation, reactive oxygen/nitrogen species, and mitochondrial permeability transition. Drug Metab Rev 2004, 36:805-822.

19. Larson AM: Acetaminophen hepatotoxicity. Clin Liver Dis 2007, 11:525-548.

20. Zwingmann C, Bilodeau M: Metabolic insights into the hepatoprotective role of $\mathrm{N}$-acetylcysteine in mouse liver. Hepatology 2006, 43:454-463.

21. Van Lint P, Libert C: Matrix metalloproteinase-8: cleavage can be decisive. Cytokine Growth Factor Rev 2006, 17:217-223.

22. Van Lint $P$, Wielockx $B$, Puimège $L$, Noël $A$, López-Otin $C$, Libert $C$ Resistance of collagenase-2 (matrix metalloproteinase-8)-deficient mice to TNF-induced lethal hepatitis. J Immunol 2005, 175(11):7642-7649.

23. Fink MP: Matrix metalloproteinase- 8 as a potential drug target for the therapy of sepsis. Crit Care Med 2012, 40:655-656.

24. Zhou X, Lu J, Chen D, Wang W, Cai Q, Li T, Zhang J: Matrix metalloproteinase-8 inhibitors mitigate sepsis induced myocardial injury in rats. Chin Med J (Engl) 2014, 127(8):1530-1535.

25. Flora G, Gupta D, Tiwari A: Preventive efficacy of bulk and nanocurcumin against lead-induced oxidative stress in mice. Biol Trace Elem Res 2013, 152:31-40.

26. Saidi S, Azaza M, Windmolders P, van Pelt J, El-Feki A: Cytotoxicity evaluation and antioxidant enzyme expression related to heavy metals found in tuna by-products meal: an in vitro study in human and rat liver cell lines. Exp Toxicol Pathol 2013, 65(7-8):1025-1033.

27. Vera-Ramirez L, Perez-Lopez P, Varela-Lopez A, Ramirez-Tortosa M, Battino M, Quiles JL: Curcumin and liver disease. Bio Factors 2013, 39:88-100.

28. Zhang L, Gavin T, Geohagen BC, Liu Q, Downey KJ, LoPachin RM: Protective properties of 2-acetylcyclopentanone in a mouse model of acetaminophen hepatotoxicity. J Pharmacol Exp Ther 2013, 346(2):259-269.

29. Tarasub N, Junseecha T, Tarasub C, Na Ayutthaya WD: Protective effects of curcumin, vitamin C, or their combination on cadmium-induced hepatotoxicity. J Basic Clin Pharm 2012, 3(2):273-281.

30. Bancroft JD, Gamble M: Theory and Practice of Histological Techniques. 6th edition. Philadelphia: Churchill Livingstone Elsevier; 2008:126-127.

31. Kheradpezhouh E, Panjehshahin MR, Miri R, Javidnia K, Noorafshan A, Monabati A, Dehpou AR: Curcumin protects rats against acetaminopheninduced hepatorenal damages and shows synergistic activity with $\mathrm{N}$-acetyl cysteine. Eur J Pharmacol 2010, 628:274-281.

32. Yousef MI, Omar SA, El-Guendi Ml, Abdelmegid LA: Potential protective effects of quercetin and curcumin on paracetamol-induced histological changes, oxidative stress, impaired liver and kidney functions and haematotoxicity in rat. Food Chem Toxicol 2010, 48:3246-3326.

33. Evans JL, Goldfine ID, Maddux BA, Grodsky GM: Oxidative stress and stress activated signaling pathways: a unifying hypothesis of type 2 diabetes. Endo Rev 2002, 23:599-622.

34. Del Rio D, Stewart AJ, Pellegrini N: A review of recent studies on malondialdehyde as toxic molecule and biological marker of oxidative stress. Nutr Metab Cardiovasc Dis 2005, 15:316-328.

35. Priyadarsini KI, Maity DK, Naik GH, Kumar MS, Unnikrishnan MK, Satav JG, Mohan $\mathrm{H}$ : Role of phenolic $\mathrm{O}: \mathrm{H}$ and methylene hydrogen on the free radical reaction and antioxidant activity of curcumin. Free Radical Biol Med 2003, 35:475-484.

36. Wright JS: Predicting the antioxidant activity of curcumin and curcuminoids. J Mol Struct (Theochem) 2002, 591:207-217.

37. Reyes-Gordillo K, Segovia J, Shibayama M, Vergara P, Moreno MG, Muriel P. Curcumin protects against acute liver damage in the rat by inhibiting NF-kappaB, proinflammatory cytokines production and oxidative stress. Biochim Biophys Acta 2007, 1770:989-996.

38. Maheswari RK, Singh AK, Gaddipati J, Srimal RC: Multiple biological activities of curcumin: a short review. Life Sci 2006, 78:2081-2087.

39. Samuhasaneeto $S$, Thong-Ngam D, Kulaputana O, Suyasunanont D, Klaikeaw $\mathrm{N}$ : Curcumin decreased oxidative stress, inhibited NF-kappaB activation, and improved liver pathology in ethanol-induced liver injury in rats. J Biomed Biotechnol 2009, 2009:981963.

40. Joe B, Lokesh BR: Role of capsaicin, curcumin and dietary n-3 fatty acids in lowering the generation of reactive oxygen species in rat peritoneal macrophages. Biochim Biophys Acta 1994, 1224:255-263.

41. Ganjali S, Sahebkar A, Mahdipour E, Jamialahmadi K, Torabi S, Akhlaghi S, Ferns G, Parizadeh SM, Ghayour-Mobarhan M: Investigation of the effects of curcumin on serum cytokines in obese individuals: a randomized controlled trial. Sci World J 2014, 2014:898361. 6 pages.

42. Yang SQ, Lin HZ, Yin M, Albrecht JH, Diehl AM: Effect of chronic ethanol consumption on cytokine regulation of liver regeneration. Am J Physiol 1998, 275:G696-G704.

43. Jurenka JS: Anti-inflammatory properties of curcumin, a major constituent of Curcuma longa: a review of preclinical and clinical research. Altern Med Rev 2009, 14:141-153.

44. Fiorentino DF, Zlotnik A, Mosmann TR, Howard M, O'Garra A: IL-10 inhibits cytokine production by activated macrophages. J Immunol 1991, 147:3815-3822.

45. Pestka S, Krause CD, Sarkar D, Walter MR, Shi Y, Fisher BB: Interleukin-10 and related cytokines and receptors. Annu Rev Immunol 2004, 22:929-979.

46. Moore KW, de Waal MR, Coffman RL, O'Garra A: Interleukin-10 and the interleukin-10 receptor. Annu Rev Immunol 2001, 19:683-765.

47. Anderson SP, Cattley RC, Corton JC: Hepatic expression of acute-phase protein genes during carcinogenesis induced by peroxisome proliferators. Mol Carcinog 1999, 26:226-238.

48. Richardson TA, Morgan ET: Hepatic cytochrome P450 gene regulation during endotoxin-induced inflammation in nuclear receptor knockout mice. J Pharmacol Exp Ther 2005, 314:703-709.

49. Kuribayashi T, Seita T, Honjo T, Yamazaki S, Momotani E, Yamamoto S: Impairment of a (2)-macroglobulin synthesis in experimental hepatopathic rats treated with turpentine oil. Exp Anim 2012, 61:125-130.

50. Lyoumi S, Tamion F, Petit J, Déchelotte P, Dauguet C, Scotté M, Hiron M, Leplingard A, Salier J, Daveau M, Lebreton JP: Induction and modulation of acute-phase response by protein malnutrition in rats: comparative effect of systemic and localized inflammation on interleukin- 6 and acute-phase protein synthesis. J Nutr 1998, 128:166-174.

doi:10.1186/1472-6882-14-457

Cite this article as: Soliman et al: Immunohistochemical and molecular study on the protective effect of curcumin against hepatic toxicity induced by paracetamol in Wistar rats. BMC Complementary and

Alternative Medicine 2014 14:457.

\section{Submit your next manuscript to BioMed Central and take full advantage of:}

- Convenient online submission

- Thorough peer review

- No space constraints or color figure charges

- Immediate publication on acceptance

- Inclusion in PubMed, CAS, Scopus and Google Scholar

- Research which is freely available for redistribution 